\title{
LEITURAS TRANSMÍDIA DE LITERATURA POR DESIGN: (SUB)VERSÕES DO CÂNONE NO ENSINO FUNDAMENTAL ॥
}

\author{
TRANSMEDIA READING OF LITERATURE BY DESIGN: \\ (SUB)VERSIONS OF CANON IN THE ELEMENTARY SCHOOL
}

\author{
Bruno Cuter Albanese
}

\begin{abstract}
RESUMO
Este artigo tem como principal objetivo analisar o processo de leitura do texto literário por um grupo de alunos do nono ano do ensino fundamental em um trabalho de adaptação da obra Senhora de José de Alencar para um curta-metragem. Os registros da pesquisa, coletados durante uma pesquisa-ação em uma escola da rede particular de ensino, foram triangulados de maneira a entender o processo de apropriação do romance em três mudanças significativas entre a obra de Alencar e a obra dos alunos. As análises foram baseadas na articulação dos conceitos de leitura subjetiva do texto literário (ROUXEL, 2012, 2013; LANGLADE, 2013; JOUVE, 2013) e do designer de significados (GRUPO DE NOVA LONDRES, 1996; COPE E KALANTZIS, 2009). Os resultados das análises mostram que o processo de leitura subjetiva da obra literária envolveu a construção de uma trajetória em que os alunos ressignificaram elementos do romance que não lhes eram familiares ou coerentes com suas experiências de mundo, por meio de elementos de seus próprios repertórios, especialmente a partir de referências de mídias audiovisuais, construindo leituras que atravessam diferentes mídias. Também foi possível afirmar a partir das análises que as narrativas transmídia em um projeto de leitura literária permitem que os alunos se apropriem do texto literário canônico de maneira a torná-lo parte de sua própria coleção e não mais como um elemento do repertório escolar que tem seu sentido estabelecido à priori da leitura.

Palavras-Chave: ensino de literatura; multiletramentos; leitura subjetiva; ensino fundamental II.
\end{abstract}

\section{ABSTRACT}

This article aims to analyze the reading process of ninth-grade students of an Elementary school based on their final work on adapting the novel "Senhora" by José de Alencar into a short film. Data gathering occurred through action research conducted at a private institution and triangulated to understand the process of appropriation of the novel in three significant changes between the work of Alencar and the work produced by the students. The analyses were carried out upon the interrelation between the concept of subjective reading of the literary text (ROUXEL, 2012, 2013; LANGLADE, 2013; JOUVE, 2013) and designs of meanings (THE NEW LONDON GROUP, 1996; COPE \& KALANTZIS, 2009). The results show that the subjective reading process of the literary work involved the construction of a trajectory in which students resignified elements of the novel that they were not familiar with or were coherent to their world of experience and own repertoires, especially those from their audiovisual media references. It was also possible to assert from the analysis that transmedia narratives in the literary reading project allowed students to appropriate the literary text while making it part of their collection and not only as part of a school repertoire since its meaning was established on the reading process aprioristically.

Keywords: literature teaching; multiliteracies; subjective reading; elementary school.

\section{A LEITURA LITERÁRIA EM TEMPOS DE MULTILETRAMENTOS}

Existe espaço para práticas multiletradas no ensino de Literatura?

Nos primórdios deste século, a inserção da disciplina de Literatura dentro da área "Linguagens, códigos e suas tecnologias" nas Orientações Curriculares para o Ensino Médio (BRASIL, 2006) já havia despertado a indignação de alguns teóricos, como Perrone-Moisés (2006), que anunciaram o desaparecimento da Literatura de nossas escolas em virtude de uma preferência pela linguagem multimidiática em relação à linguagem verbal. Portanto, para alguns, os letramentos para além da letra representariam uma ameaça ao letramento literário. Essa visão, de certa maneira, pode ser encontrada nas próprias partes da OCEM dedicadas ao ensino de Literatura, escrita por Osakabe e Frederico (2006), quando os autores sugerem que é interessante o diálogo com outras áreas, como a de artes, mas de uma maneira que as fronteiras entre as disciplinas não sejam quebradas. Apesar de ser mantida como um campo dentro da área de "Linguagens e suas tecnologias", a mesma preocupação também aparece no nosso documento mais recente, a Base Nacional Comum Curricular (BRASIL, 2018). Nela, o texto literário é colocado como base principal do trabalho com a Literatura, ressaltando a importância de não o substituir por outros gêneros artísticos, como filmes e histórias em quadrinhos.

\footnotetext{
* Doutor em Linguística Aplicada pela Universidade Estadual de Campinas (Unicamp), Campinas, SP, Brasil. brunocalbanese@gmail.com Orcid: https://orcid.org/0000-0002-9646-2263
} 
Nesse sentido, a relação da Literatura com outras formas de linguagem dentro do campo educacional é permeada por tensões que envolvem o risco de sua simplificação e de seu apagamento. Por outro lado, Durão (2012) aponta para uma crise nos estudos literários que diz respeito ao lugar da Literatura e, principalmente, da Teoria Literária, em um mundo em que os meios de socialização e construção identitárias se dão cada vez menos pela letra e mais pelas imagens. Dessa forma, o autor argumenta que a relevância do estritamente literário diminui através da disseminação do computador e da internet, porém, isso não significa que outras mídias e linguagens não possam ser aliadas da Literatura:

é possível defender que há zonas de interseção, que as adaptações mantêm vivas as obras literárias e que Shakespeare nunca foi tão conhecido, sem dúvida é possível defender que a informática alarga e fortalece a literatura, ao invés de ameaçá-la. [...] De uma forma ou de outra, em maior ou menor grau, está em jogo um ajuste de um meio ao outro, por mais que o encontro entre eles possa ser suave, produtivo, ou mutuamente benéfico (DURÃO, 2012, p.196, grifo do autor).

Posto isso, o autor percebe um espaço de diálogo entre as práticas de letramento literário e as práticas de multiletramentos. Diálogo esse que também defendo ser potencialmente benéfico para o campo educacional. Na mesma linha defendida por Agazzi (2014), argumento que o grande impasse contemporâneo do ensino de Literatura é em como promover estratégias de aproximação entre os alunos e os textos literários que propicie uma experiência literária. Se por um lado, os gêneros de outras linguagens não podem substituir a capacidade da Literatura como forma de ampliar nossa visão e percepção de mundo pelo arranjo especial das palavras (BRASIL, 2018), a leitura literária com foco nas correntes literárias, na biografia do autor e na fortuna crítica da obra também colocam a Literatura em perigo na escola, pois causam o afastamento dos estudantes do prazer da leitura (AGAZZI, 2014).

Dufays (2007), Rouxel (2012), entre outros pesquisadores ${ }^{1}$, identificaram problemas semelhantes na educação literária da França. Refletindo e teorizando sobre o assunto, os autores argumentam que esse afastamento é causado principalmente pela exclusão dos alunos do processo de leitura literária, sendo que este deveria ser sobretudo uma experiência de encontro entre a obra e a subjetividade dos discentes que resultaria na transformação tanto do alunoleitor quanto do texto. Mais uma vez o desafio se coloca em como proporcionar esse encontro.

Para Agazzi (2014), as estratégias de aproximação devem ter como ponto de partida o mundo dos alunos. É nesse gancho que considero potencialmente benéfico o diálogo entre as práticas de letramento literário com as práticas de multiletramentos, uma vez que, como afirma Daley (2010), a linguagem multimidiática das telas é parte do vernáculo corrente dos estudantes do século XXI. Portanto, nesse sentido, promover a leitura literária dentro de projetos de multiletramentos pode ser uma estratégia para proporcionar experiências subjetivas com o texto literário.

A partir dessa premissa, desenvolvi o projeto de ensino "Cinema Literário" junto aos meus alunos do Nono Ano do Ensino Fundamental II que envolveu a leitura do romance Senhora, de José de Alencar, para a produção de um filme curta-metragem. Com base nas evidências coletadas durante essa pesquisa-ação ${ }^{2}$, o objetivo deste artigo é analisar como se deu o processo subjetivo de leitura literária dentro de um projeto de multiletramentos, identificando os mecanismos de leitura utilizados e examinando os recursos do romance e de outras fontes que foram mobilizados para compor a narrativa dos alunos. Dessa forma, discuto o potencial de outras formas de linguagem para a educação literária.

Para isso, faz-se importante primeiramente delinear a perspectiva de educação literária a qual me alinho.

\section{O LEITOR LITERÁRIO: UM DESIGNER DE SIGNIFICADOS}

Como mencionado anteriormente, Dufays (2007), Rouxel (2012; 2013), Jouve (2013) e Langlade (2013) possuíam uma mesma problemática de pesquisa que os impulsionaram a teorizar sobre o ensino de Literatura: entender o porquê de os alunos franceses terem tanta dificuldade e, até mesmo, rejeição à leitura de textos literários. Segundo Rezende (2013), apesar das diferenças culturais, políticas e sociais, França e Brasil vivem uma crise parecida no ensino de Literatura, podendo considerar que em ambos os países a educação literária é fracassada.

1. Também fazem parte dos grupos de pesquisa que formularam e discutem essa teoria Gérard Langlade, Michele Petit, Vincent Jouve e Jean Bellemin-Nöel.

2. Por trabalhar com seres humanos, essa pesquisa foi aprovada pelo Conselho de Ética e Pesquisa da Unicamp. Número do CAAE: 34333614.3.0000.5404. Os responsáveis legais pelos alunos assinaram o Termo de Consentimento Livre e Esclarecido em que autorizaram a gravação e o uso da imagem dos participantes. 
O primeiro problema identificado por Rouxel $(2013$, a) é a concepção de Literatura e de cultura literária que orientam a educação tradicional. A representação ainda presente sobre Literatura é " [...] um grupo autônomo de texto com finalidade estética" (ROUXEL, 2012, p.15). Ou seja, a Literatura se define somente pelo fator estético, tendo papel nela mesma. Dessa forma, a autora aponta que a cultura literária escolar se define por um grupo de obras canônicas de valor legitimado na cultura comum formado a partir de um suposto consenso. Portanto, o objetivo educacional em apresentar essas obras é para o aluno ter domínio desse conhecimento valorizado, tornando o texto literário um "objeto" a ser adquirido e não uma experiência de leitura para a fruição (ROUXEL, 2013 a).

A didática que se instala a partir dessas orientações transforma a leitura em uma análise formal e objetiva do texto, que pode ser considerada erudita, mas também não permite engajamento ético, estético e/ou fantástico do aluno-leitor como sujeito (ROUXEL, 2013, c). Para Rezende (2013), quando o leitor é impedido de interagir com o texto, não há leitura. E se não há leitura, não há Literatura. Langlade (2013) considera que esse distanciamento demandado pela leitura erudita é essencial para que os leitores profissionais, como os críticos literários, possam avaliar o valor estético dessa obra. No entanto, para o autor, essa leitura se torna problemática quando é considerada a única forma de interação com o texto, sendo que o objetivo da educação literária não deveria ser o de formar críticos literários, mas sim leitores literários.

Conforme Langlade (2013), dentro da abordagem tradicional, os distúrbios, as emoções, os devaneios, as associações que emergem da personalidade profunda do leitor, de sua história pessoal e de suas recordações literárias são considerados elementos que falseiam e embaçam a leitura literária. $\mathrm{O}$ autor defende uma mudança radical dessa visão, argumentando que seriam justamente essas "viagens" do leitor aprendiz os sinais de que o aluno está se apropriando da obra. Define-se assim o leitor subjetivo: um leitor construído pelas experiências de leitura fundadoras da infância que trabalham com o fantástico e o envolvimento afetivo. Dessa forma, ler é constituir um trajeto de leitura. Para Bellemin-Nöel (2001) apud Langlade (2013), o trajeto de leitura é tecido pela combinação dos elos da vida do leitor com a trama dos enunciados que foram combinados pelo autor. Por essa razão, Langlade (2013) afirma que a leitura é o espaço no qual a escrita se choca com as lembranças, as imagens mentais, as representações de si e dos outros, ou seja, é o encontro entre a escrita e a memória.

O resultado desse encontro, segundo Rouxel (2012), é um texto diferente daquele que o autor escreveu: é o texto do leitor. Esse texto, completa a autora, é uma hibridização entre o texto do autor e o imaginário do leitor, possibilitando, para Langlade (2013), que o leitor habite a obra. Assim sendo, Rouxel (2013, a) entente que a leitura subjetiva seria o que Eco (1996) considera que seja utilizar o texto. Utilizar, conforme Eco (1996), é quando o leitor busca um significado do texto para si, baseando-se na sua própria experiência sobre o mundo para imaginar e ficcionalizar sobre o texto. Rouxel (2013a) adverte que o foco na leitura subjetiva, no uso do texto, não representa uma não necessidade de a obra possuir um sentido social ou da apresentação de conhecimentos literários, mas antes, principalmente no contexto educativo, o texto precisa fazer sentido para o leitor. Dessa maneira, Rouxel (2013 a) critica Eco (1996), pois para o autor a utilização seria uma atividade inferior em relação à interpretação, a qual seria o processo de busca pelo significado social da obra.

Investigando a forma como ocorre o processo de encontro entre o leitor e o texto, Rouxel e Langlade (2013) e Jouve (2013) delineiam dois tipos de leitura subjetiva: a necessária e a acidental. A necessária ocorre quando o texto espera e encoraja o leitor a habitar a obra (ROUXEL \& LANGLADE, 2013; JOUVE, 2013). Já a acidental é quando a obra não exige que o leitor ficcionalize, porém ele o faz de qualquer forma (JOUVE, 2013). Rouxel e Langlade (2013) chamam a atenção para o fato de que é na leitura acidental que os professores, erroneamente, consideram que houve uma falta de compreensão da obra pelo aluno, porque ele não entendeu o sentido pretendido pelo autor.

Jouve (2013) considera que ambos processos podem se dar em planos diferentes: o afetivo, orientando pela emoção, e o intelectual, orientado pela cognição. Ao se cruzar os dois processos de leitura (necessária e acidental) com os dois planos (afetivo e intelectual), o autor propõe uma tipologia dos mecanismos de leitura subjetiva:

- Subjetividade Necessária Afetiva: a impossibilidade de o escritor literário traduzir em palavras toda a composição do cenário, do figurino, forma física das personagens, bem como os entornos em que ação se desenrola constroem espaços vazios na obra que convidam o leitor a criar imagens mentais das cenas do texto. Jouve (2013) considera esse processo afetivo, pois construímos essas imagens mentais usando nosso próprio passado, principalmente por meio de memórias que possuem valor particular. 
- Subjetividade Necessária Intelectual: Jouve (2013) nos lembra que a Literatura é considerada indireta, porque ela representa algo ao invés de dizer explicitamente sobre algo. Nesse jogo de representações, de insinuações, são criados pontos de incerteza nos quais o leitor é obrigado a tomar decisões. Dufays (1994) apud Jouve (2013) apresenta quatro causas diferentes para o surgimento desses pontos: a ambiguidade, quando a unidade textual tem mais de um sentido; o branco, quando informações necessárias fazem falta; o resíduo, quando uma unidade semântica não se integra à obra; e, por fim, a contradição, quando há incompatibilidade na obra.

- Subjetividade Acidental Afetiva: o processo de mudança das diretrizes emocionais da obra. Segundo Jouve (2013), é um mecanismo que emerge da identificação do leitor com uma personagem ou situação da obra, por isso da ordem do afetivo, e essa identificação provoca no leitor uma reação emocional diferente daquela esperada ou mais usual das leituras socialmente já construídas da obra. Por exemplo, quando o leitor se identifica mais com o antagonista do que com o protagonista e torce pelo primeiro, quando supostamente deveria torcer para o segundo.

- Subjetividade Acidental Intelectual: esse processo, chamado também de interleitura, é similar ao da intertextualidade, porém uma intertextualidade não construída a partir do próprio texto e sim pelo leitor. Diferentemente da intertextualidade, Rouxel (2013 b) aponta que a interleitura não exige que a relação entre textos tenha sido feita materialmente em marcas textuais pelo autor. É um processo em que o leitor, subjetivamente, tece relações entre as obras. Nas palavras do cunhador do termo, "designa a rede de relações que um leitor estabelece entre textos mesmo se o texto em questão não fornece explicita e textualmente as indicações que permitem a construção dessa rede" (BELLEMIN-NOEL, 2001, p.12 apud ROUXEL, 2009, p.180).

A partir da descrição destes quatro processos de leitura subjetiva do texto literário, Jouve (2013) torna claro o ponto de Rouxel (2013) de que no trajeto de leitura formado entre a escrita do autor e a memória do leitor, este constrói um novo texto, o texto do leitor (ROUXEL, 2012). Essa percepção da leitura como um ato de construção de sentidos que transforma tanto o texto quando ao leitor dialoga com a noção de leitura por design. Para Kalantzis et al (2020), o processo de leitura envolve a conexão do leitor com o texto a partir das lembranças de significados e de modelos mentais que ele já possui sobre o mundo. Sendo assim, o leitor constrói sentidos sobre o texto, transformando-o, da mesma forma que esse novo texto passa a ser uma nova lembrança, sendo o leitor transformado. Conforme os autores, o leitor é então um designer de significados.

A noção de designer de significados surgiu em 1996 no manifesto do Grupo de Nova Londres (doravante, GNL), chamado A Pedagogy of Multiliteracies: desiging social futures. Nesse artigo, os autores expandiram o conceito de letramento, que se referia estritamente às práticas sociais do uso da linguagem verbal em suas variedades formais, cunhando o termo multiletramentos, para que também se reconhecesse a diversidade semiótica e cultural que compõem as práticas letradas da contemporaneidade. Além desse ponto teórico, o GNL (1996) também se preocupou em propor uma nova pedagogia para abordar as práticas multiletradas em sala de aula, expandindo tanto a agência do aluno frente ao seu processo educativo quanto abandonando o foco educacional nas competências e habilidades para usos determinados da gramática e do cânone literário. Buscando uma perspectiva mais relevante, inovadora, criativa e emancipadora, Cope e Kalantzis $(2009$, p.10) a noção de design se tornou central para a pedagogia dos multiletramentos. Segundo os autores, "design, no sentido de construção, é algo que você faz no processo de representação de sentidos, para você mesmo nos processos de produção de sentido como ler, ouvir ou ver" ${ }^{\prime \prime}$.

A partir desse conceito, a produção de sentidos é entendida como um processo dinâmico e ativo (GRUPO DE NOVA LONDRES, 1996), ou seja, todos as linguagens, incluindo a língua, devem ser compreendidas como modos em constante transformação e não de reprodução (COPE E KALANTZIS, 2009). Para Cope e Kalantzis (2009), portanto, os alunos nunca foram somente reprodutores daquilo que lhes era ensinado, mas é a escola que não reconhecia o papel deles como produtores e transformadores de sentido. Da mesma forma que apontam Langlade (2013) e Rouxel (2012), por mais que a imaginação, os pensamentos, os sentimentos dos alunos sejam considerados perigosos para o ensino, pois os desviariam de atingir o significado social do texto (ROUXEL, $2013 \mathrm{c}$ ), eles sempre estiveram presentes. No entanto, nunca foram validados como formas em que o aluno torna o texto seu.

Se não se vê o aluno mais como mero reprodutor, os objetivos educacionais também se transformam, deixando de ser determinadas competências e habilidades. Conforme Cope Kalanztis (2009, p.10), o objetivo dessa nova pedagogia é "formar um tipo de pessoa, um designer de significados ativo, sensível à diferença, à mudança e à inovação.

3. Tradução minha para "Design in the sense of construction is something you do in the process of representing meanings, to oneself in sensemaking processes such as reading, listening or viewing" 
A lógica da Pedagogia dos Multiletramentos é uma que reconhece que a produção de sentidos é uma atividade, um processo transformador".

Mais uma vez, Cope e Kalantzis (2009) tratam de uma maneira mais ampla o que Rouxel (2012) trata especificamente sobre o ensino de Literatura. Para a autora, o objetivo da leitura de obras literárias na escola é propiciar o encontro das memórias dos alunos com os enunciados arranjados pelo autor. Dessa forma, durante a leitura, o aluno-leitor construiria o seu próprio texto, bem como se transformaria e se conheceria. Minha defesa é que esse processo é semelhante ao processo de design descrito pelo GNL (1996), e que, combinando os dois processos, é possível compreender o processo de design da leitura subjetiva dos textos literários. Antes, no entanto, é necessário retomar o processo do GNL (1996) em seus três momentos: available designs, desiging e redesigned.

Os available designs são os recursos que o designer tem para produzir sentidos colecionados durante suas experiências no mundo. Estes recursos são, portanto, lembranças provindas de diferentes mídias, culturas e formas de linguagem (COPE \& KALANTZIS, 2009; KALANTZIS et al, 2020). O GNL (1996) compreende que os availables designs podem ser a própria gramática de cada uma das formas de linguagem; ou os padrões e convenções de uso dessas linguagens; e, por fim, um objeto específico que faz parte do repertório do designer, ou seja, uma música, um filme, um romance.

No processo de leitura, o momento de conexão do leitor com o texto, o momento da construção de sentidos, é o designing (KALANTZIS et al, 2020). Para o GNL (1996), o designing se inicia quando o designer passa a combinar e rearticular os availables designs de forma a produzir novos sentidos por meio de reapresentações e recontextualizações. Os autores também alertam que o grau de transformação depende do grau de controle do contexto, mas que por mais autoritário que ele seja, sempre há algum novo sentido sendo construído, podendo ter maior ou menor grau de transformação dependendo do contexto, mas nunca a mera reprodução. Cope e Kalantzis (2009) relembram que o processo de designing possui duas características importantes: é subjetivo e agenciador.

Subjetivo, porque trabalha com o material armazenado do próprio designer em suas experiências de vida. Ao mesmo tempo é agenciador, pois o designer seleciona e articula o material de maneira a contemplar seus próprios interesses. Por essas duas características é que o GNL (1996) considera o designing como processo de transformação. O resultado desse processo é o redesigned.

Como aponta Cope e Kalantzis (2009), o redesigned é uma nova produção de conhecimento em um processo de aprendizagem. No caso da leitura, Kalantzis et al (2020) consideram que o redesigned são os sentidos que o leitor constrói para um texto. Dessa forma, o texto é transformado. É importante ressaltar que o leitor também se modifica após o processo de designing, uma vez que o redesigned passa a ser um novo available design para si próprio, rearticulando sua subjetividade (GNL, 1996; KALANTZIS ET AL, 2020).

As duas principais proposições da teoria da Leitura Subjetiva referem-se ao fato de que o leitor se apropria da obra literária, transformando-a em uma obra do leitor (ROUXEL, 2012) e que essa transformação ocorre de maneira singular por meio dos elementos de sua subjetividade (LANGLADE, 2013). Duas noções semelhantes podem ser encontradas na perspectiva do design: o produto do designing é uma produção de sentido distinta que apresenta uma nova representação do mundo (GRUPO DE NOVA LONDRES, 1996), construída de forma única a partir de conexões com as lembranças discursivas e padrões de produção de sentido que foram colecionadas através da vida do designer (COPE E KALANTZIS, 2009; KALANTZIS ET AL, 2020).

No processo de leitura subjetiva por design, o leitor tem como seus available designs o próprio texto literário (a obra do autor), além de, como relembra Langlade (2013), tudo aquilo que constitui as memórias do leitor. No designing, ou seja, no processo de articulação e recontextualização dos available designs, o leitor transforma a obra original em um tecido formado por suas memórias e pelos enunciados articulados pelo autor. Como Jouve (2013) nos mostra, essas conexões podem ser mobilizadas por quatro mecanismos subjetivos: a subjetividade necessária intelectual e afetiva e a subjetividade acidental intelectual e afetiva. Ao final desse processo de leitura, forma-se o texto do leitor (ROUXEL, 2012), um texto diferente da obra original, o que o GNL (1996) chama de um redesigned. Graficamente, posso representar esse processo da seguinte forma: 


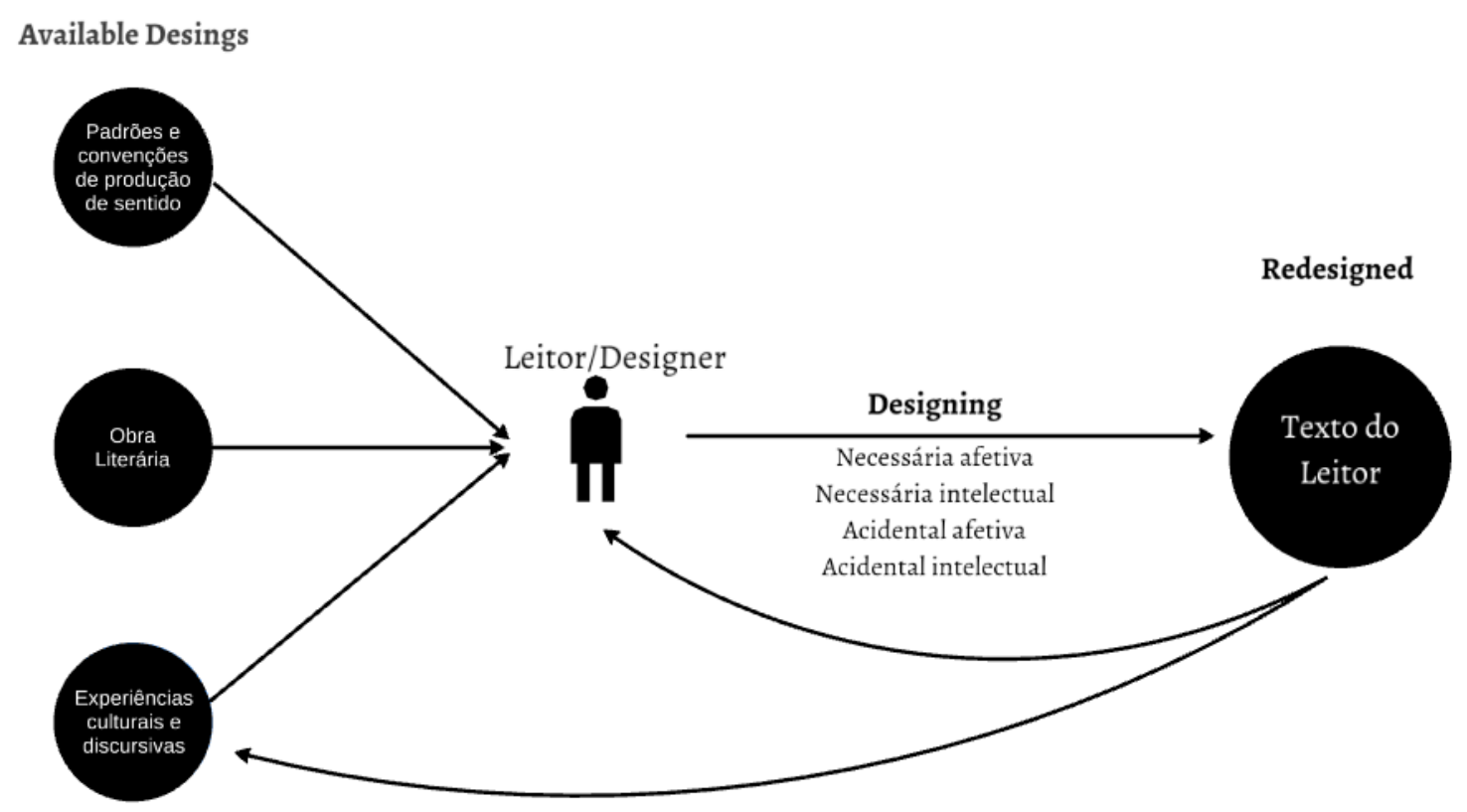

Figura 1. Processo de leitura subjetiva por design Fonte: Elaboração própria

Percorrido o trajeto teórico em que se sustentam as análises, trato de breves questões metodológicas sobre a natureza da pesquisa e a forma de geração e análise dos dados.

\section{CINEMA LITERÁRIO: DO PROJETO DE ENSINO À PESQUISA-AÇÃO}

Conforme caracterizam Lankshear e Knobel (2008), a pesquisa-ação no campo educacional se caracteriza pela fusão do papel de professor com o do pesquisador, em que o professor-pesquisador pode investigar e refletir sobre os resultados de suas próprias práticas educativas. Como ocupei esses dois papeis durante o desenvolvimento do projeto de ensino "Cinema Literário" e, neste artigo, reflito sobre as experiências educativas em relação ao ensino de Literatura, considero que os dados aqui analisados são resultados de uma pesquisa-ação.

O projeto "Cinema Literário" propunha para os meus alunos do Nono Ano do Ensino Fundamental II que lessem o romance Senhora, de José de Alencar, e, com base nessa leitura, produzissem um curta-metragem. Para que isso acontecesse, dividi o projeto em quatro etapas, sendo que em cada uma delas foram coletados diferentes tipos de registros:

- a leitura do romance: foram realizadas rodas de leitura em que discutíamos as interpretações dos alunos sobre a obra. Após cada aula, escrevi um diário de campo, relatando as discussões.

- oficinas sobre a linguagem cinematográfica: ministrei quatro oficinas sobre como escrever, produzir e gravar um filme. Essas oficinas foram gravadas em vídeo.

- a escrita do roteiro: em sala de aula, os alunos conjuntamente escreveram o roteiro que serviria de base para o curta-metragem. Nessa etapa, também escrevi um diário de campo e recolhi a versão final do roteiro.

- gravação e edição do curta: no contra turno, os alunos produziram, estrelaram e editaram o filme. O curta-metragem de 20 minutos também foi recolhido.

Com os registros devidamente coletados, deu-se início à geração dos dados. Contrastando a obra de Alencar com o filme dos alunos, busquei por diferenças de conteúdo entre os dois enredos, pois entendo que essas modificações seriam os momentos que os alunos-leitores se tornaram autores da obra (LANGLADE, 2013). Foram encontradas três grandes diferenças: a personagem Dona Firmina se tornou o mordomo Firmino; a personagem Tio Lemos se tornou o advogado Dr. Lemos; e o motivo para Fernando precisar de dinheiro deixou de ser o reestabelecimento dos 
dotes das irmãs para uma dívida com a máfia. Para cada uma dessas modificações, foi reconstruído o trajeto de leitura dos alunos, buscando nos diários de campo e no roteiro como se deram esses processos.

Osa dados gerador foram organizados dentro das categorias de aprendizagem por design (GNL, 1996):

- available designs: trechos modificados do romance de Alencar.

- designing: trechos dos diários de campo e do roteiro.

- redesigned: trechos do curta-metragem.

Por fim, a partir da construção teórica apresentada na sessão anterior, a leitura literária por design foi analisada por meio dos quatro mecanismos de subjetivação propostos por Jouve (2013): necessária afetiva, necessária intelectual, acidental afetiva, e acidental intelectual.

Após as análises, percebeu-se que as três trajetórias indicavam um padrão na forma como o processo de leitura aconteceu, tanto do ponto de vista dos mecanismos, quanto dos recursos externos ao romance. Tendo isso em mente, bem como as limitações de extensão do artigo, preferiu-se apresentar a análise de somente um desses momentos de apropriação: a transformação da personagem Dona Firmina no mordomo Firmino.

\section{UMA TRAJETÓRIA TRANSMÍDIA}

No romance Senhora, a protagonista Aurélia perdeu toda sua família ainda muito moça. A última pessoa que lhe restava, sua mãe, morreu inesperadamente. Por essa razão, a jovem foi levada para morar com Dona Firmina Mascarenhas, uma viúva que tinha um parentesco distante com Aurélia. A viúva aceitou que a, até então, pobre menina ficasse morando com ela. No entanto, a vida de Aurélia mudou quando seu desconhecido avô paterno morreu, deixando-lhe toda herança. Seu tio Lemos, que não havia ajudado a sobrinha, tornou-se seu tutor e insistiu que a jovem fosse morar com ele, mas ela recusou a oferta e exigiu que morasse sozinha na companhia de Dona Firmina.

Firmina é descrita logo no começo do livro como uma velha parenta que acompanhava Aurélia em todos os lugares. É deixado claro que, por Aurélia, a presença da viúva seria desnecessária, pois já governava sua casa e sua própria vida como queria e sem pedir nenhum tipo de autorização a ninguém. No entanto, para a sociedade, essa postura emancipada de uma jovem solteira seria malvista, fazendo com que Aurélia necessitasse da presença de Firmina.

Ao decorrer da história, o narrador revela mais sobre essa relação e percebe-se que havia realmente um pagamento para que Firmina ficasse por perto de Aurélia, para que a sociedade acreditasse que havia alguém controlando a vida da moça. Mas, dentro do seio familiar, Dona Firmina era uma dama de companhia de Aurélia e responsável por realizar as vontades dela. É importante frisar que a relação entre as duas, apesar de hierarquicamente estabelecida, não era desprovida de afeto. Em vários momentos do livro são narradas cenas de afeto, nas quais se percebe uma relação de muitos cuidados e companheirismo entre as duas mulheres. Firmina sempre se despedia de Aurélia com um beijo na testa e se ofereceu para ajudá-la a se preparar para a noite de núpcias, papel que era desempenhado pelas mães das noivas na época.

Como mostra o GNL (1996), mesmo nas atividades usualmente consideradas pela escola como de recepção e não produção de significados, como a leitura, são oferecidos recursos para que o leitor ressignifique a obra, ou seja, para que ele faça um designing de sentidos. Nessa lógica, a personagem Dona Firmina era para de um available design que os alunos poderiam se utilizar para construir o curta: uma senhora de idade, que ocupava a posição de dama de companhia de Aurélia, zelando por seu bem-estar e lhe fazendo companhia.

No entanto, este recurso disponibilizado pelo romance não foi suficiente para os alunos. Recontextualizar a obra em um novo tempo demandava que os alunos tivessem mais informações. Para isso, eles realizaram uma leitura subjetiva necessária intelectual, já que havia um espaço em branco, ou seja, havia poucas informações sobre Dona Firmina, o que exigiu que os alunos completassem com outros conteúdos de seus próprios repertórios. Umm primeiro incômodo, um primeiro espaço em branco foi com a função da personagem Dona Firmina.

Como mostro no relato do meu diário de campo, os alunos estavam com dificuldade de repensar como Dona Firmina faria parte da história, pois para eles não fazia mais sentido a existência de uma dama de companhia, eles nem sabiam o que isso significava ao certo. O que faz a personagem existir na história é justamente o fato de Aurélia precisar de uma companhia para ir aos eventos da sociedade, que se tornaram, na trama dos alunos, uma "balada". Para 
eles, não fazia nenhum sentido uma senhora acompanhar uma jovem em uma "balada". Com a recontextualização que fizeram da trama, Dona Firmina se tornava, dentro da leitura deles, incoerente com o resto da história. É justamente nesses momentos em que o texto literário não oferece informações suficientes ou que as informações não são coerentes com o texto que o leitor está formando que a obra torna necessário o engajamento intelectual de quem a lê. Questionar a permanência de Dona Firmina na história e buscar uma nova função para ela são os indícios de uma subjetivação necessária intelectual por parte dos alunos.

No meu diário de campo, está registrado que a solução que eles encontraram foi sugerida pelo aluno Pedro Paulo ao propor que Dona Firmina se tornasse Firmino, o mordomo gay inspirado em Crô, personagem da novela Fina Estampa

Em linhas gerais, o mordomo quebrava com o estereótipo dos mordomos engravatados, sérios e discretos das grandes mansões. Crô era gay, participava ativamente da vida dos patrões e se vestia de modo não padrão para um mordomo. A construção da personagem, tanto pelo ator quanto pelas figurinistas, remetia a uma visão estereotipada dos gays. Marcello Serrado falava com uma voz aguda e modificada, sempre com as mãos na cintura ou com os pulsos quebrados. O figurino da personagem era colorido, com o uso de muitas cores consideradas femininas, agarrado ao corpo e com muitos acessórios. Esta visão estereotipada sobre o homossexual também era motivada pelo papel cômico que a personagem tinha na novela.

Uma questão se somava à construção física da personagem para garantir a comicidade. Crô era extremamente devotado a sua patroa, tanto para lhe prestar serviços como para dividir segredos íntimos. "Soberana de Luxo", "Majestosa rainha das terras férteis"; "Magnâmica de Tebas" eram algumas das formas que a personagem se referia à Tereza Cristina, revelando que para ele sua patroa era como uma rainha. A patroa, fazendo valer seus codinomes, utilizava de sua posição para humilhar e fazer de Crô seu capacho.

A personagem Crô é trazida pelo aluno Pedro Paulo como outro available design para solucionar o problema de como atualizar Dona Firmina. Com Dona Firmina e Crô como available designs, começou então o processo de designing.

No capítulo II da primeira parte do livro, Aurélia estava em seu quarto pela manhã, após ter ido a um baile na noite anterior. Ainda um pouco ensonada, ela foi surpreendida pela entrada de Dona Firmina no quarto. A viúva perguntou se ainda estava cansada da festa e Aurélia respondeu que estava um pouco fraca, mas por conta do calor. Dona Firmina começou a criticar o fato de os bailes começarem muito tarde e outras impressões que teve do evento. Aurélia então perguntou o que sua parenta achava sobre Amaralzinha, uma moça que tinha ido pela primeira vez ao baile da sociedade, e quem entre elas era mais bonita e educada.

Firmina, tentando responder à moça com a franqueza que lhe foi requerida, afirmou que, sem sombra de dúvidas, Aurélia era mais bonita e educada que a outra. A viúva tentou continuar embasando sua resposta, mas a jovem não mais lhe ouvia. Indo embora do quarto, Dona Firmina percebeu que Aurélia começou a se arrumar, passar perfume e se maquiar. Para a senhora, aquelas perguntas e atitudes de Aurélia revelavam que ela estava a tramar algo.

Sentadas à mesa na hora do almoço, Dona Firmina tinha mais certeza que algo havia acontecido com Aurélia na festa da noite anterior e que, provavelmente, tinha a ver com um pretendente. No decorrer da história, Aurélia não contou para sua parenta o que estava planejando, mas o leitor descobre que Firmina estava certa: a jovem começou a planejar como se casaria com Fernando Seixas.

Ao roteirizar esse trecho, os alunos já atuaram na ressignificação, ou seja, no designing da obra por meio da hibridização da personagem Firmina e Crô:

4. A novela Fina Estampa foi televisionada pelo canal Globo em seu horário nobre, durante o período 22 de agosto de 2011 a 23 de março de 2012. A trama girava em torno da relação conflituosa entre Griselda, uma mulher humilde que ganhou uma fortuna na loteria, e Tereza Cristina, uma milionária que disputou seu marido com Griselda. Tereza Cristina, interpretada por Christiane Torloni, vivia em sua mansão sendo servida pelo seu fiel mordomo, Crodoaldo Valério, interpretado por Marcello Serrado, sendo chamado por seu apelido "Crô". 
Tabela 1. Trecho do roteiro

Cena 7
Aurélia acorda em seu quarto, após uma noite de festa. Levanta-se e vai tomar café-da-manhã com seu fiel amigo Firmino.
Firmino, sentado na mesa: Bom dia, madame! Humm, pelo jeito a festa foi boa.
Aurélia, sentando-se com ele: Como todas as outras, Firmino.
Firmino: Alguém especial?
Aurélia: Não. Como sempre, todos inferiores.
Firmino: Á́, amiga, que bad! Você está precisando de um bofe ur-gen-te.
Aurélia, com sorriso maldoso: Fique calmo, amigo, já tenho todo o plano em mente.
Firmino: Aí, não acredito. Me conta o babado.
Aurélia: Te conto, mas não conte para ninguém.
Firmino: Tranquilo, amiga, eu sou um túmulo.
Aurélia: Lembra-se quando eu te contei do Fernando Seixas?
Firmino: Como me esquecerei desse bofe, amiga.
Telefone toca.
Aurélia: Tenho assuntos a tratar.
Aurélia saí.

Fonte: Arquivo do Pesquisador

Aqui há uma fusão dos modos de se relacionar entre Aurélia e Dona Firmina com a relação entre Tereza Cristina e Crô, não ficando claro o que Firmino é em relação à Aurélia. Os alunos iniciam o trecho dizendo que Firmino é um amigo fiel de Aurélia, o que indica uma relação que não é estabelecida no romance, nem na novela. No entanto, a primeira vez que ele usa um vocativo para falar com Aurélia, ele a chama de "madame", fazendo remissão à personagem Crô, que sempre se referia a sua patroa de maneira a hierarquizar a relação dos dois: Tereza Cristina em posição de poder e Crô de subalterno. Aurélia responde a ele chamando-o de Firmino, portanto mantendo uma distância entre as personagens. Mas na continuação das falas, eles se referem um ao outro como amigo/amiga, voltando a uma relação de proximidade entre as personagens.

Entendo que esta tensão em como construir a relação entre Aurélia e Firmino mostra o processo ainda de negociação entre os alunos de estabelecerem o que Firmino terá de Crô e o que terá de Dona Firmina. Ele deve ter uma relação mais aberta com Aurélia, mas ainda respeitando a hierarquia patroa/empregado? Ou a relação deve ser mais distante, porém mais afetuosa como Aurélia e Dona Firmina?

$\mathrm{Na}$ verdade, essas próprias tensões existiam nas tramas que deram origem a essas personagens. Dona Firmina tinha uma relação de carinho e afeto com Aurélia, mas ao mesmo tempo estava ali para fazer tudo que a moça desejasse. E Crô tinha uma relação íntima com Tereza Cristina, no entanto, ela nunca o deixava esquecer que ele era seu empregado. Os alunos representam este conflito no roteiro: por um lado, Aurélia e Firmino se tratam como amigos, mas por outro, ele a chama de madame, hierarquizando a relação.

Nesse trecho, diferentemente do livro em que Dona Firmina desconfia de algum possível flerte de Aurélia, Firmino pergunta para Aurélia sobre os relacionamentos amorosos dela e faz sugestões sobre o assunto. Também, diferente do livro em que Aurélia não comenta nada sobre os seus planos com Dona Firmina, a Aurélia do roteiro já mostra uma relação mais íntima com Firmino e confidencia o segredo. Esta característica remete à personagem do vídeo mais o Crô, que participava ativamente dos planos maldosos da patroa.

Por fim, já é perceptível que os alunos iniciam a construção de Firmino com marcas estereotipadas de uma personagem gay. Apesar de não haver descrições do que Firmino usa ou faz, o roteiro apresenta algumas representações do vocabulário que estaria ligado ao estereótipo da fala gay: o próprio fato de um homem chamar uma mulher de "amiga"; a palavra bofe para se referir a um homem com atrativos sexuais; o uso de gírias em inglês, como "bad". Além do vocabulário, há uma escansão silábica na pronúncia da palavra "urgente", indicando que cada uma das sílabas deve ser pronunciada separadamente. Essa maneira de pronunciar para destacar uma palavra também faz parte do estereótipo da fala de um homossexual. Firmino poderia ser uma personagem gay construída de diferentes maneiras, 
mas os alunos já mostram uma intenção de construí-la a partir do modelo em que Crô foi construído: atendendo a todos os lugares comuns do comportamento de um gay. Segundo Almeida (2011), a forma de falar, agir e se vestir de forma mais semelhante a performance hegemônico do feminino em relação a hegemônica do masculino são traços que os programas televisivos utilizam para a construção de personagens gays, reproduzindo e reforçando o estereótipo de que todo gay é afeminado.

As negociações e ressignificações que Dona Firmina sofre ao ser interpelada pela personagem Crô só serão finalizadas no produto final, ou seja, é no curta-metragem que a personagem Firmino será um redesigned.

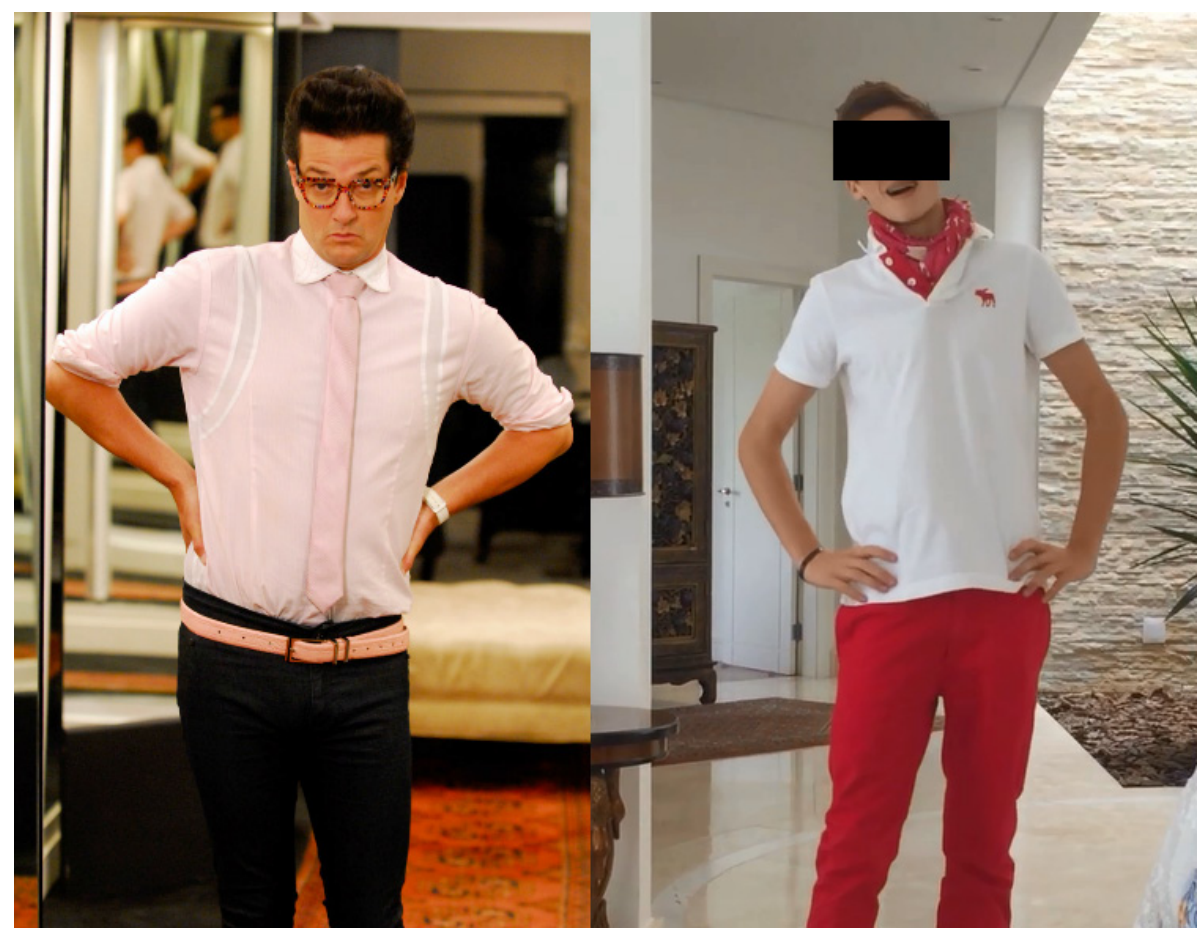

Figura 2. Crô e Firmino

Fonte: Arquivo do Pesquisador

${ }^{5}$ Em primeiro lugar, vejamos a construção física da personagem em comparação com Crô. Olhando para a personagem Crô (à esquerda) e para a personagem Firmino (à direita) fica bastante clara a inspiração daquela sobre esta. Principalmente através de dois elementos: o figurino e o desempenho do ator.

Quanto ao figurino, ficam claras as referências de estilo: uma calça skinny, que fica mais justa ao corpo; a blusa de gola que revela um pouco de formalidade; o acessório no pescoço que também demonstra a tentativa de tornar o figurino mais elegante; e, por fim, o mesmo penteado de cabelo. Toda essa composição começa a indicar a formulação de um figurino estereotipicamente homossexual, em que os tons rosas servem como o arremate da construção. Em nossa cultura, a associação de tons rosas, tido como tons femininos, em roupas mais formais e o uso do acessório, como o lenço, remetem a uma preocupação feminina com a aparência que é ainda relacionada, no senso comum, somente a homens gays.

Para reforçar a ideia da personagem gay, tanto o ator Marcelo Serrado, que dá vida a Crô, quanto o aluno Pedro Paulo fazem uso de diversos maneirismos também considerados gays, como a mão na cintura, o rebolado no andar e a "fala mole", que já havia aparecido como preocupação na produção do roteiro.

Abaixo seguem os frames das duas primeiras cenas em que o personagem Firmino aparece no curta. Os quatro primeiros frames correspondem ao momento em que ele vai ao quarto de Aurélia acordá-la. Os seguintes correspondem à cena trazida no roteiro acima.

5. Em Albanese (2019), faço uma discussão voltada para as questões identitárias/culturais mobilizadas durante o processo de leitura da obra e, a partir delas, destacar a importância do professor de Literatura como um mediador cultural. Não me escapa que a construção da personagem Firmino permite a discussão sobre diferentes representações sobre as identidades sociais, o que, inclusive, também faz parte das discussões dos multiletramentos. No entanto, dadas as limitações de um artigo, focalizo a análise dentro do recorte estabelecido pelos objetivos. 


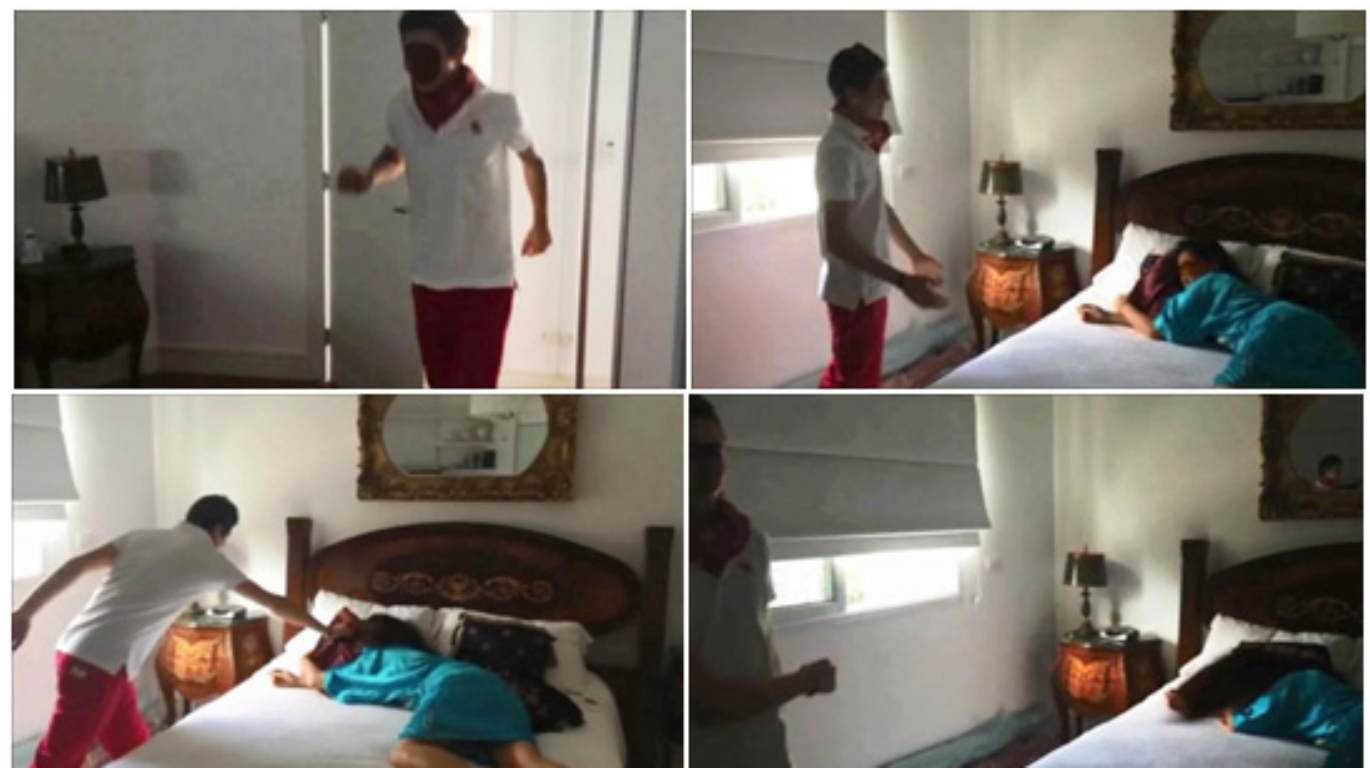

Figura 3. Firmino acorda Aurélia

Fonte: Arquivo do Pesquisador

Tabela 2. Trecho do curta

\section{Descrição e Diálogos da Cena}

Frame 1: Firmino anda na ponta dos pés para dentro do quarto de Aurélia, em direção as cortinas.

Frame 2: Depois de deixar o quarto mais claro e Aurélia abrir os olhos, ele diz:

-Bom dia, flor.

Aurélia responde, cobrindo o rosto com uma almofada.

-Sai daqui.

Frame 3: Então, ele tira a almofada com que Aurélia cobriu seu rosto

Frame 4: E diz:

-Te espero para o café.

Em seguida, arremessa a almofada em direção ao rosto de Aurélia acertando-a.

Fonte: Arquivo do Pesquisador

Como vimos acima, a construção física da personagem Firmino é a mesma da personagem Crô, tanto no que tange o desempenho do ator, quanto ao figurino. Nada nesse sentido remete à personagem do romance Dona Firmina. Portanto, o que resta saber é se os alunos ao produzirem o texto do leitor, no nosso caso o curta, simplesmente trocaram o nome de Crô para Firmino e todo o resto foi imitado sem alguma reflexão crítica, ou se eles realmente conseguiram hibridizar a personagem da novela com a do romance.

Apesar de parecer que Firmino não tem nenhuma influência de Dona Firmina além de seu nome, uma questão mostra que Firmino é um redesigned de Crô com Firmina e não só a cópia de Crô. O fato de a relação de Aurélia e Firmino no vídeo nunca ser desrespeitosa e Firmino nunca sofrer humilhações de Aurélia mostra uma influência da relação carinhosa entre Aurélia e Dona Firmina. Firmino é o mordomo de Aurélia: ele a acorda; ele acomoda a cadeira dela na hora em que ela vai se sentar; ele recebe os convidados dela. Apesar disso, o relacionamento construído entre as duas personagens é de amizade e companheirismo, permitindo que os dois brinquem um com o outro, como quando Firmino arremessa a almofada no rosto de Aurélia, e confidenciem segredos, como na cena acima em que Aurélia conta a Firmino sobre seu pretendente. Esta relação não se encontra entre Crô e sua patroa na novela Fina Estampa, pois apesar de ser um mordomo confidente e escudeiro, Crô era tratado como um subalterno. Dona Firmina, apesar de também receber um salário para ficar com Aurélia, nunca é tratada como uma empregada por sua patroa. Firmina cumpre com todos os desejos da moça, mas ainda assim tem uma relação carinhosa com Aurélia.

Nesse sentido, considero que Firmino é um redesigned, pois é o resultado de uma apropriação dos available designs que os alunos possuíam para a construção de algo novo. Firmino comporta-se, veste-se e tem o mesmo tipo de humor 
que Crô, todavia, sua função no curta não é a de capacho e bedel de Aurélia, mas sim, a de ser o companheiro e amigo de Aurélia que zela por sua felicidade, o que remete muito mais à personagem de Dona Firmina.

Por essa razão, considero que os alunos resolveram a questão da função de Dona Firmina na história através de uma leitura subjetiva acidental intelectual. Como aponta Jouve (2013), neste tipo de processo os leitores criam relações intertextuais entre textos sem que elas tenham sido marcadas pelo autor. Em momento nenhum da novela Fina Estampa entende-se que a personagem Crô tenha sido inspirada em Dona Firmina, no entanto, como os alunos tinham esses dois available designs, eles criaram essa relação. A partir deste processo de interleitura entre Dona Firmina e Crô, articulando características dos dois recursos, os alunos produziram um novo recurso: Firmino.

Esta nova personagem pode participar da trama do romance de maneiras distintas das quais a personagem que lhe inspirou participa da história de Alencar. No romance, Fernando e Aurélia tentavam a todo o momento disfarçar para a viúva o que realmente se passava entre os dois. Em somente algumas passagens do livro, a senhora percebia que a relação dos noivos podia estar um pouco abalada, mas, de maneira geral, ela acreditava que os dois eram felizes. Pela posição que ocupa, por outro lado, Firmino sabia de absolutamente tudo o que se passava na vida de Aurélia e Fernando. No roteiro, os alunos escreveram uma cena em que Firmino acompanha Aurélia até a casa de Adelaide, até então noiva de Fernando, para persuadirem a moça a abandonar seu noivo. Esta cena não foi gravada, porque eles acharam que ela não seria tão importante para a história e o curta já estava longo demais.

No entanto, em outra cena presente no roteiro e no curta-metragem, Firmino confirma sua posição de amigo de Aurélia dentro da trama ao chamar os recém-casados para alertá-los que as pessoas já desconfiavam do fracasso do casamento dos dois. Este momento não existe no romance de Alencar: nem Dona Firmina ou qualquer outra personagem entrou em contato com os protagonistas para aconselhá-los ou alertá-los sobre qualquer tipo de rumor, portanto esta cena foi inteiramente desenvolvida pelos alunos para criar tensão dentro da história, pois, a partir deste aviso, Fernando e Aurélia davam e frequentavam festas para mostrar a todos que o casamento ia bem. Vejamos a cena:

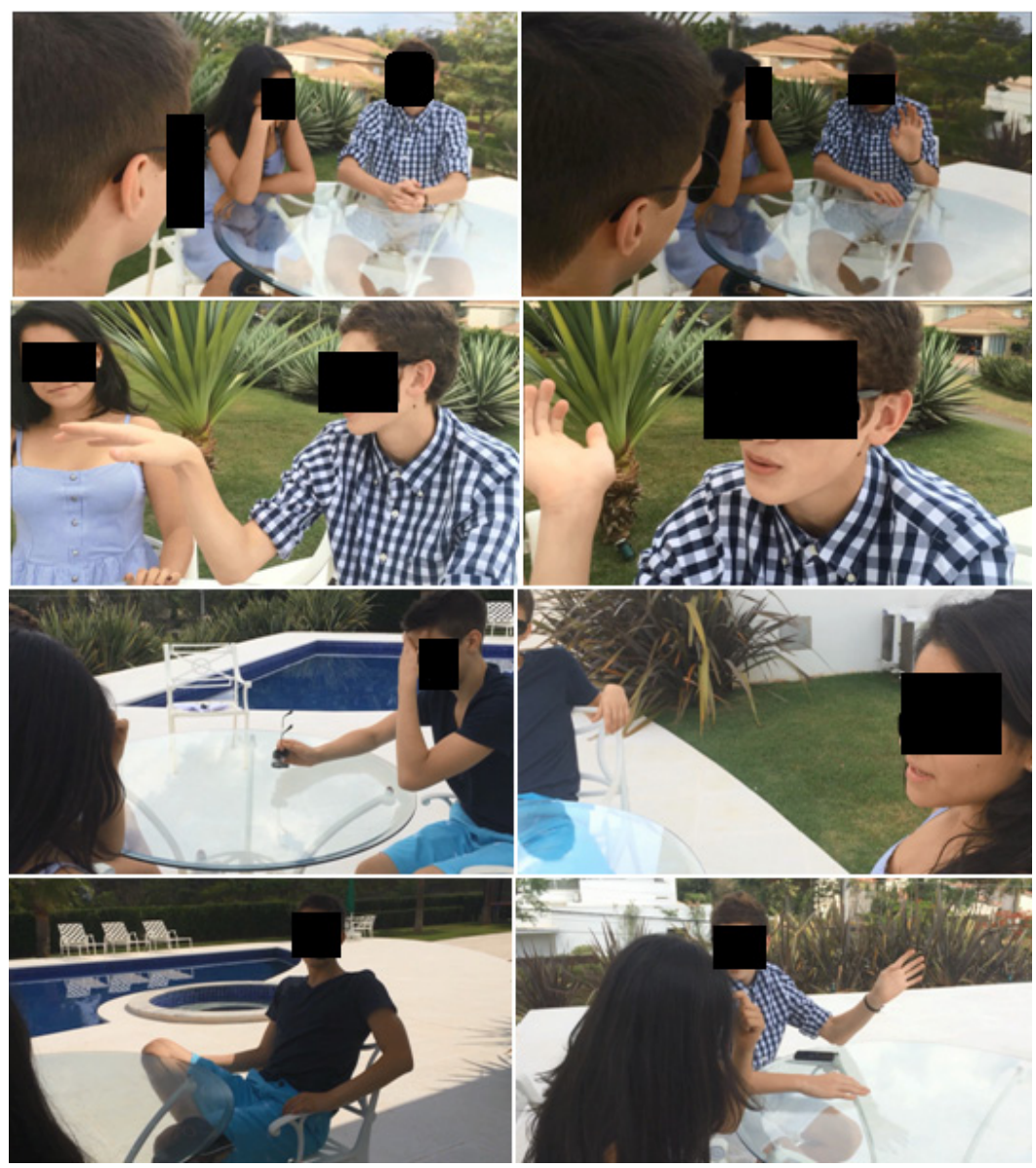

Figura 4. Conversa entre Aurélia, Fernando e Firmino

Fonte: Arquivo do Pesquisador. 
Tabela 3. Trecho do curta

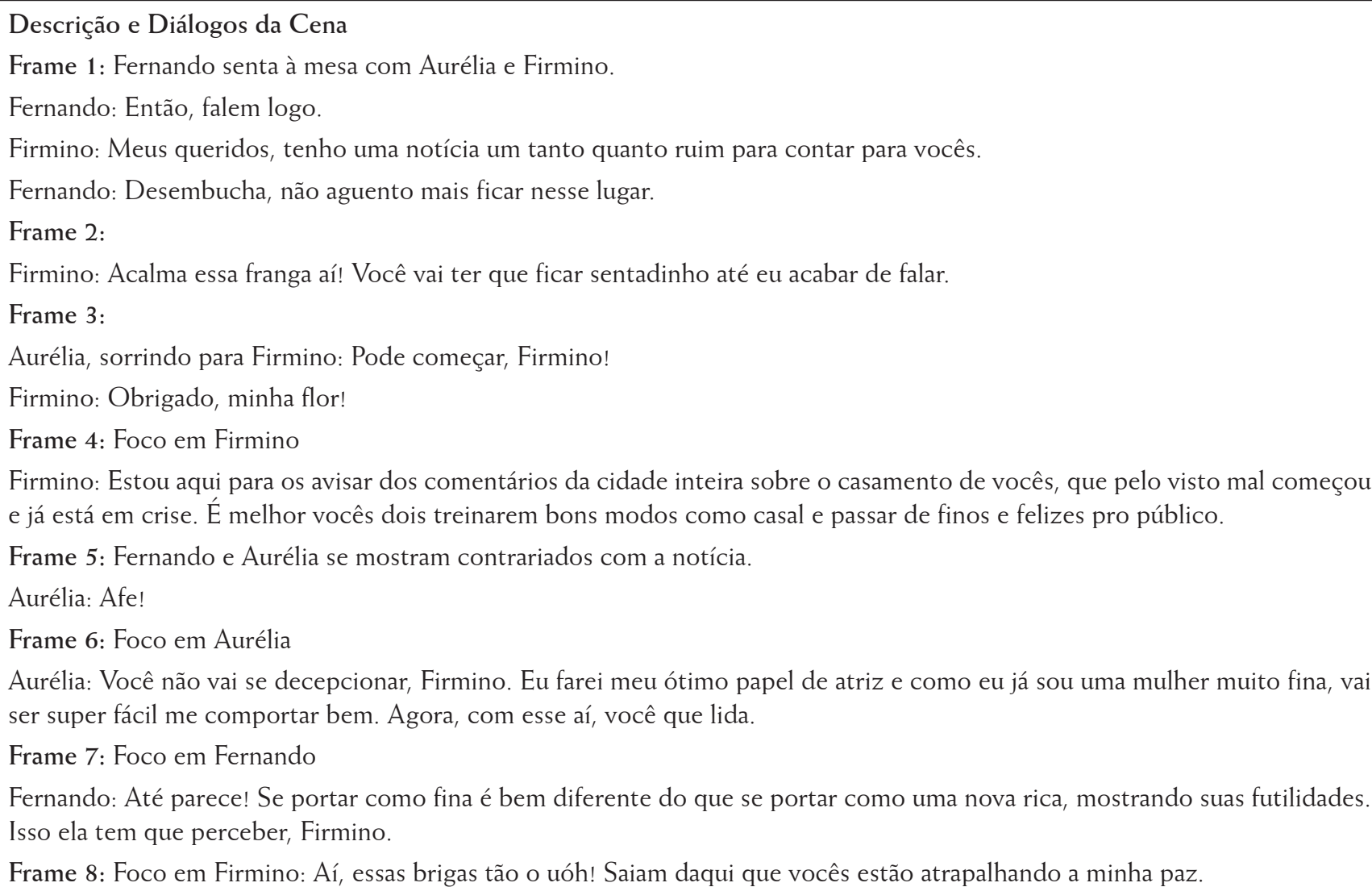
Fonte: Arquivo do Pesquisador.

Esta cena só é possível porque alguém conhecia realmente o que se passava no seio conjugal de Aurélia e Fernando. No romance, mesmo os mais próximos do casal acreditavam que os noivos eram muito felizes. No curta, porém, com a presença do amigo íntimo de Aurélia, existe a personagem que sabia do plano de Aurélia de humilhar Fernando e que, portanto, poderia interferir no que se passava dentro da casa. Como na cena acima, Fernando e Aurélia trocam acusações na frente de Firmino e ele se sente irritado por presenciar mais uma briga, dizendo: "essas brigas estão uóh!". Portanto, Firmino tinha conhecimento das brigas entre o casal, diferente de Dona Firmina. A viúva nunca poderia fazer a mesma intervenção, pois ela não tinha conhecimento dos planos de sua pupila. Portanto, o designing de Dona Firmina através da personagem Crô trouxe novas possibilidades para a personagem dentro da trama. A personagem deixa de ser uma acompanhante de Aurélia e expectadora da trama para ser alguém que constrói os rumos da história junto com os protagonistas.

Ao mesmo tempo, é interessante notar que Crô, dentro da novela Fina Estampa, também não poderia tomar uma atitude como a de Firmino em chamar o casal para aconselhar e advertir, pois, apesar da intimidade que possuía com sua patroa, ele nunca deixou de ser o empregado capacho. Na cena, Firmino está sentado à mesa com Aurélia e Fernando se senta com eles, os três conversam em pé de igualdade. Se Firmino fosse só o mordomo, ele nunca estaria sentando à mesma mesa de seus patrões. Além disso, ele se refere ao casal como "meus queridos" e depois a Aurélia como "minha flor", mostrando não só intimidade com o casal, como também carinho. Por fim, outra atitude que mostra que Firmino não é somente o mordomo bajulador da patroa é que ele se sente à vontade para pedir que Aurélia e Fernando se retirem de sua presença, pois eles estão o irritando. Crô, por mais confidente que fosse de sua patroa e ela precisasse/gostasse de sua companhia, nunca teria a chance de ordenar nada a ela.

Considero que essa cena me permite afirmar que Firmino ao ser o redesigned de Dona Firmina e Crô, ou seja, ao ser o texto do leitor que uniu os elos do texto de Alencar com outros recursos trazidos pelos alunos, não só possui características das duas personagens, como essa combinação das características abre novas possibilidades para a personagem dentro da história. Evidenciando um terceiro mecanismo de leitura: a acidental afetiva, pois existem transformações nas diretrizes emocionais da obra. Firmino conhece toda a intimidade de sua patroa como Crô, é gay como Crô. Firmino tem o mesmo nome de Dona Firmina, é tratado na casa de Aurélia com o mesmo respeito 
e carinho que Dona Firmina. Esses recursos que os alunos selecionaram dos availables designs permitem que Firmino seja, antes de qualquer coisa, o amigo de Aurélia. Sendo o amigo fiel da protagonista, ele ganha destaque dentro da trama. Apesar de Pedro Paulo considerar que Crô seria um equivalente de Dona Firmina e adicionaria o efeito cômico ao curta-metragem, os alunos construíram a personagem de tal maneira que ela causou transformações na história e momentos de criação completamente independentes do romance.

Diante disso, a trajetória de leitura foi a seguinte: primeiramente, através de uma subjetivação necessária intelectual, os alunos perceberam que a Dona Firmina não seria um recurso com função na história trazida para os dias atuais, principalmente porque seu papel no romance não era coerente com as experiências de vida dos alunos. Para a personagem não ser simplesmente descartada, em uma subjetivação acidental intelectual, os alunos buscaram em seu repertório algo com que pudessem relacionar Firmina e, dessa forma, garantir à personagem um papel na história. Nesse processo, a personagem Crô, mordomo gay da novela Fina Estampa, foi mobilizada como outro available design. A partir desses dois recursos, eles continuaram com o designing, articulando características das duas personagens e desenvolvendo um novo recurso, Firmino. Não é possível deixar de falar que Firmino acaba por transformar as diretrizes emocionais da obra ao adicionar um efeito cômico que vem da sua inspiração em Crô. Com a transformação de Dona Firmina em Firmino, a trama ganha um humor estereotipado bem diferente da seriedade da obra de Alencar. Por essa mudança, evidencia-se também houve um processo de leitura subjetiva acidental afetiva.

Essa trajetória foi construída, portanto, por meio de três mecanismos de leitura subjetiva articulados: a necessária intelectual, causada por estranhamentos entre o mundo ficcional e o mundo dos alunos; a acidental intelectual, como forma de solucionar esses estranhamentos os estudantes trouxeram um recurso de seus repertórios audiovisuais em um processo de interleitura; por fim, a acidental afetiva, uma vez que a combinação dos recursos da obra e do repertório audiovisual formava uma personagem diferente que abria possibilidades para a história, transformando as diretrizes emocionais. A trajetória descrita a partir desse dado repetiu-se com as outras duas diferenças entre o romance de Alencar e o curta-metragem dos alunos. Percebe-se, portanto, um padrão na forma como o processo de leitura literária ocorreu para a transformação da obra em um filme.

A questão que se coloca é: quais as implicações desse processo para o ensino de Literatura?

\section{LEITURA TRANSMÍDIA, LEITORES TRANSMÍDIA: IMPLICAÇÕES PARA O ENSINO DE LITERATURA}

Como colocado na introdução deste artigo, a relação do ensino de Literatura com outras linguagens é um ponto de tensão em que o contato com o texto literário é ameaçado por substituições ou simplificações. No entanto, a partir das análises realizadas na sessão anterior, argumento que outras linguagens podem estabelecer um diálogo benéfico com os estudos da literatura em sala de aula. Afirmo isso porque um projeto de multiletramentos envolvendo a leitura de Literatura ofereceu uma estratégia para aproximar os alunos do texto literário.

Retomando o alerda de Agazzi (2014), as didáticas atuais colocam a Literatura em perigo por se centrarem nas características dos movimentos estéticos, nos contextos históricos, nas biografias dos autores e na fortuna crítica da obra, impedindo os alunos de terem uma experiência literária. Compreendo que a proposta do projeto "Cinema Literário" foi uma prática educativa que permitiu os alunos experenciarem o romance Senhora, uma vez que havia a oportunidade e a autorização para os alunos se apropriassem da obra e construíssem o texto do leitor (ROUXEL, 2012; 2013 b).

A ressignificação da personagem Dona Firmina de José de Alencar na personagem de Firmino por meio da articulação com a personagem Crô da novela Fina Estampa, bem como todas as modificações no enredo que foram causados por esse processo, são sinais da apropriação da obra pelos alunos para produzirem seu próprio texto. Essa construção, como argumenta Langlade (2013), não coloca a leitura em risco, mas é evidência de que os alunosleitores puderam habitar a obra, transformando-a e transformando-se. Nesse horizonte, os sentidos da obra não são estabelecidos a priori da leitura, mas as práticas educativas permitem que os alunos atuem como designer de significados, construindo sentidos do texto literário para si próprios.

Considero importante também destacar dois desdobramentos da Teoria da Leitura Subjetiva que os dados aqui analisados permitem vislumbrar:

- a primeira é o fato de esses mecanismos de leitura subjetiva não trabalharem necessariamente separados. Quando Jouve (2013) propõem os tipos de leitura subjetiva, o autor não aponta para a possibilidade de um mecanismo 
encadear outros processos de subjetificação. Além de ser possível, esse encadeamento forma uma trajetória de leitura que perpassa toda a obra. No caso dos meus dados, a necessária intelectual propiciou a acidental intelectual, que, por sua vez, propiciou a acidental afetiva.

- o segundo fato é que essas trajetórias perpassam diferentes mídias, a leitura se torna uma experiência transmidiatica, extrapolando os limites da disciplina de Literatura. Retomando a afirmação de Daley (2010), a linguagem das telas é o vernáculo corrente dos estudantes que estão em nossas salas de aula. Sendo assim, não é estranho que os recursos mobilizados para serem articulados com as obras literárias advenham de objetos culturais de mídias audiovisuais, como filmes, novelas e séries.

Posto isso, é preciso que as práticas educativas reconheçam que os alunos da contemporaneidade são leitores transmidiáticos, recontextualizando e rearticulando recursos de diferentes linguagens e gêneros para construírem significados no mundo. Dessa forma, levantar barreiras entre o trabalho com a Literatura e outras formas de linguagem pode impedir a experiência literária na escola, cristalizando significados para os cânones que pouco ressoam aos alunos.

\section{REFERÊNCIAS}

AGAZZI, G.L.(2014). Problemas no ensino de literatura: do perigo ao voo possível. Remate de Males, v.34, n.2, p.443-458.

ALBANESE, B.C. (2019). Do propositor de significados ao mediador cultural: os papéis do professor de Literatura em um projeto de adaptação audiovisual. Calidoscópio, v.17, n.3, p.575-591.

ALMEIDA, D.M.V. (2011). "Sou gay, porém totalmente discreto" - os estereótipos e a criação do ethos em um site de relacionamento gay. ReVeLe, n.3, p.1-23.

BRASIL (2006). Orientações curriculares para o ensino médio - linguagens, códigos e tecnologias. Brasília: Ministério da Educação, Secretaria de Educação Fundamental.

BRASIL (2018). Base nacional comum curricular. Brasília: Ministério da Educação, Secretária de Educação Fundamental.

COPE, B.; KALANTZIS, M. (2009). Multiliteracies: new literacies, new learning. Pedagogies: an international journal, v.4, n.3, pp.164-195.

DALEY, E. (2010). Expandindo o conceito de letramento. Trabalbos em Linguística Aplicada, v.49, n.2, p.481-491.

DUFAYS, J.L. (2007). Enseigner et aprrendre la littérature au jourd'bui pour quoi faire?. Paris: Presses universitaires de Louvai.

DURÃO, F. (2012). A crise nos estudos literários, hoje. In: SIGNORINI, I. \& FIAD, R.S. (orgs.), Ensino de língua: das reformas, das inquietações e dos desafios. Belo Horizonte, MG: Editora da UFMG, p.191-202.

KALANTZIS, Mi; COPE, B.; PINHEIRO, P. (2020). Letramentos. Campinas: Editora da Unicamp.

KNOBEL, M.; LANKSHEAR, C (2008). Pesquisa pedagógica: do projeto à implementação. Tradução de Magda França Lopes. Porto Alegre, RS: Artmend.

JOUVE, V (2013). A leitura como retorno a si: sobre o interesse pedagógico das leituras subjetivas. In: ROUXEL, $\mathrm{A}_{\text {; }}$ LANGLADE, G; REZENDE, N. L. (orgs.). Leitura subjetiva e ensino de literatura. São Paulo, SP: Alameda, p.53-65.

LANGLADE, G (2013). O sujeito leitor, autor da singularidade da obra. In: ROUXEL, Ai LANGLADE, Gi REZENDE, N. L. (orgs.). Leitura subjetiva e ensino de literatura. São Paulo, SP: Alameda, p.25-38.

MARTIN, M. (2011). A linguagem cinematográfica. Tradução de Paulo Neves. São Paulo, SP: Brasiliense.

NEW LONDON GROUP (1996). A pedagogy of multiliteracies: designing social futures. Harward Educational Review, n.66, v. 1, p.60-92. 
NOFFKE, S.; SOMEKH, B (2005). Action Research. In: SOMEKH, B.; LEWIN, C. (orgs.).Research Methods in Social Sciences. Londres, Sage Publications, p.25-37.

PERRONE-MOISES, L. B (2006). Literatura para todos. Literatura e Sociedade, v. 11, n.9, p. 16-29.

REZENDE, N. L (2013). Apresentação ao leitor brasileiro. In: ROUXEL, A; LANGLADE, G, REZENDE, N. L. (orgs.). Leitura subjetiva e ensino de literatura. São Paulo, SP: Alameda, p.7-18.

ROUXEL, A. (2012). Mutações epistemológicas e o ensino de literatura: o advento do sujeito leitor. Tradução de Samira Murad. Revista Criação e Crítica, n.9, p.13-24.

ROUXEL, A. (2013 a). A tensão entre utilizar e interpretar na recepção de obras literárias em sala de aula: reflexão sobre uma inversão de valores ao longo da escolaridade. In: ROUXEL, A, LANGLADE, Gi REZENDE, N. L. (orgs.). Leitura subjetiva e ensino de literatura. São Paulo, SP: Alameda, p.151-164.

ROUXEL, A; LANGLADE, G; REZENDE, N. L. (2013 b) Apropriação singular das obras e cultura literária. In: ROUXEL, A; LANGLADE, G, REZENDE, N. L. (orgs.). Leitura subjetiva e ensino de literatura. São Paulo, SP: Alameda, p.165-189.

ROUXEL, A; LANGLADE, G; REZENDE, N. L. (2013 c). O advento dos leitores reais. In: ROUXEL, A; LANGLADE, G; REZENDE, N. L. (orgs.). Leitura subjetiva e ensino de literatura. São Paulo, SP: Alameda, p.191-208.

ROUXEL, A.; LANGLADE, G (2013). Apresentação dos coordenadores franceses. In: ROUXEL, A; LANGLADE, G; REZENDE, N. L. (orgs.). Leitura subjetiva e ensino de literatura. São Paulo, SP: Alameda, p.19-24.

Recebido: $15 / 7 / 2021$

Aceito: 28/9/2021

Publicado: $13 / 10 / 2021$ 